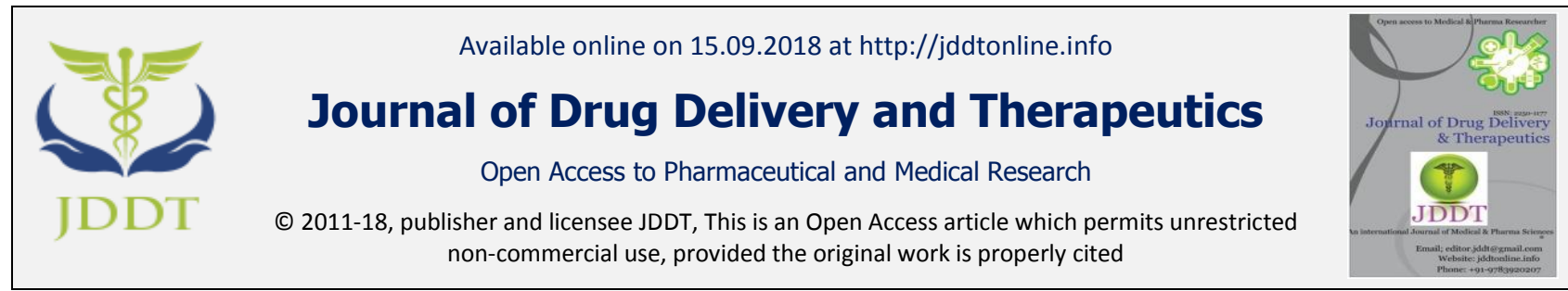

Open ${ }_{\text {Access }}$

Review Article

\title{
DEVELOPMENT OF NANOCRYSTAL FORMULATION WITH IMPROVED DISSOLUTION
}

\author{
Kaur Jaspreet * and Kumar Sandeep \\ Department of Pharmaceutics, ASBASJSM College of Pharmacy, Bela (Roper), Punjab, India
}

\begin{abstract}
With the advancement in modern pharmaceutical technologies, Nanotechnology is the one of the most establish technology which is used to improve the therapeutic index and to overcome the formulation challenges of poorly water-soluble compounds. Nanocrystals, in nano range, is the interesting approach for poorly soluble drugs. Due to the small size, increased surface area enhanced the dissolution rate and solubility of drug. In this paper, current technologies and methods in nanocrystal preparation, stabilization, pharmaceutical applications and limitations of nanocrystal are reviewed.
\end{abstract}

Keywords: Nanocrystal, limitations, stabilization, preparation, applications

Article Info: Received 08 July, 2018; Review Completed 02 Sep 2018; Accepted 09 Sep 2018; Available online 15 Sep 2018

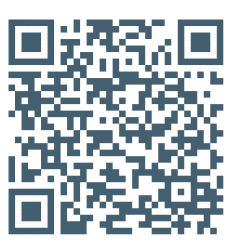

Cite this article as:

Kaur J, Kumar S, Development of Nanocrystal Formulation with Improved Dissolution, Journal of Drug Delivery and Therapeutics. 2018; 8(5):118-129 DOI: http://dx.doi.org/10.22270/jddt.v8i5.1946

*Address for Correspondence:

Jaspreet Kaur, Department of Pharmaceutics, ASBASJSM College of Pharmacy, Bela (Roper), Punjab, India

\section{INTRODUCTION}

Now days, the most important issue in drug discovery and development is the poor solubility. Lots of new chemical entities shows significant therapeutic effects, better efficiency but their clinical applications are restricted due to the poor water solubility. These types of new chemical entities in Biopharmaceutics Classification System (BCS) belongs to BCS class II or class IV. ${ }^{1}$

Therefore various types of approaches have been established to overcome the problem of low aqueous solubility. These approaches are - Salt formation, Cosolvent, Complexation and Solid state manipulation, Emulsions, Surface active agents, Micronization., ${ }^{2,3}$

The classic formulation approach is the micronization meaning the transfer of drug powders into the size range between typically $1-10 \mu \mathrm{m}$. . However, in many cases they cannot solve the bioavailability problem. A consequent next step was to move from micronization to nanonization.
'Nanonization' i.e., conversion of micronized particles to nano-sized particles is a logical step forward. Various nanonization strategies have emerged to increase the dissolution rates and bioavailability of numerous drugs that are poorly soluble in water. These strategies include increasing the surface area, changing the crystalline forms and designing novel nanomaterials that can act as carriers for controlled release. ${ }^{3,4}$

Drug nanocrystals represent a novel and versatile approach to improve solubility and bioavailability of the poorly soluble drugs. Surface modifications (increased surface area) of drug particles by nanocrystal approach impart a feature of improved adhesiveness to the surfaces. This pioneering nanocrystal technology can be combined with the conventional dosage forms to further add an advantage to the drug therapy. ${ }^{5}$

\section{Definition: Drug Nanocrystal}

Nanocrystals are crystalline nanoparticles with size ranging from 200 to $500 \mathrm{~nm}$ stabilized by surface stabilizers. They increase the saturation solubility, dissolution rate and probably the mucoadhesion 
resulting in improved oral bioavailability of drugs exhibiting dissolution rate dependent bioavailability. ${ }^{6}$

Drug nanocrystals constitute a versatile formulation approach to enhance the pharmacokinetic and pharmacodynamic properties of poorly soluble drugs.
The formulation simplicity and production scaling flexibility along with their intrinsic small particle size and large surface area make NCs stand a way unique not just among the pharmaceuticals but also among other nanoparticles. $^{7,8}$

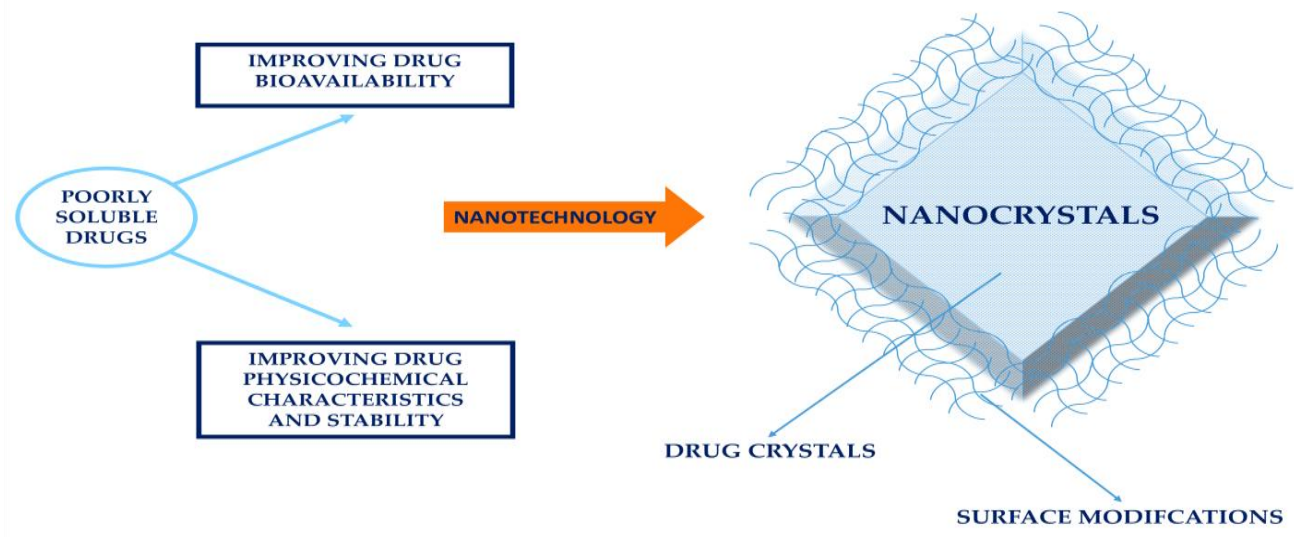

Figure 1: Nanocrystals with surface modification

\section{Advantages}

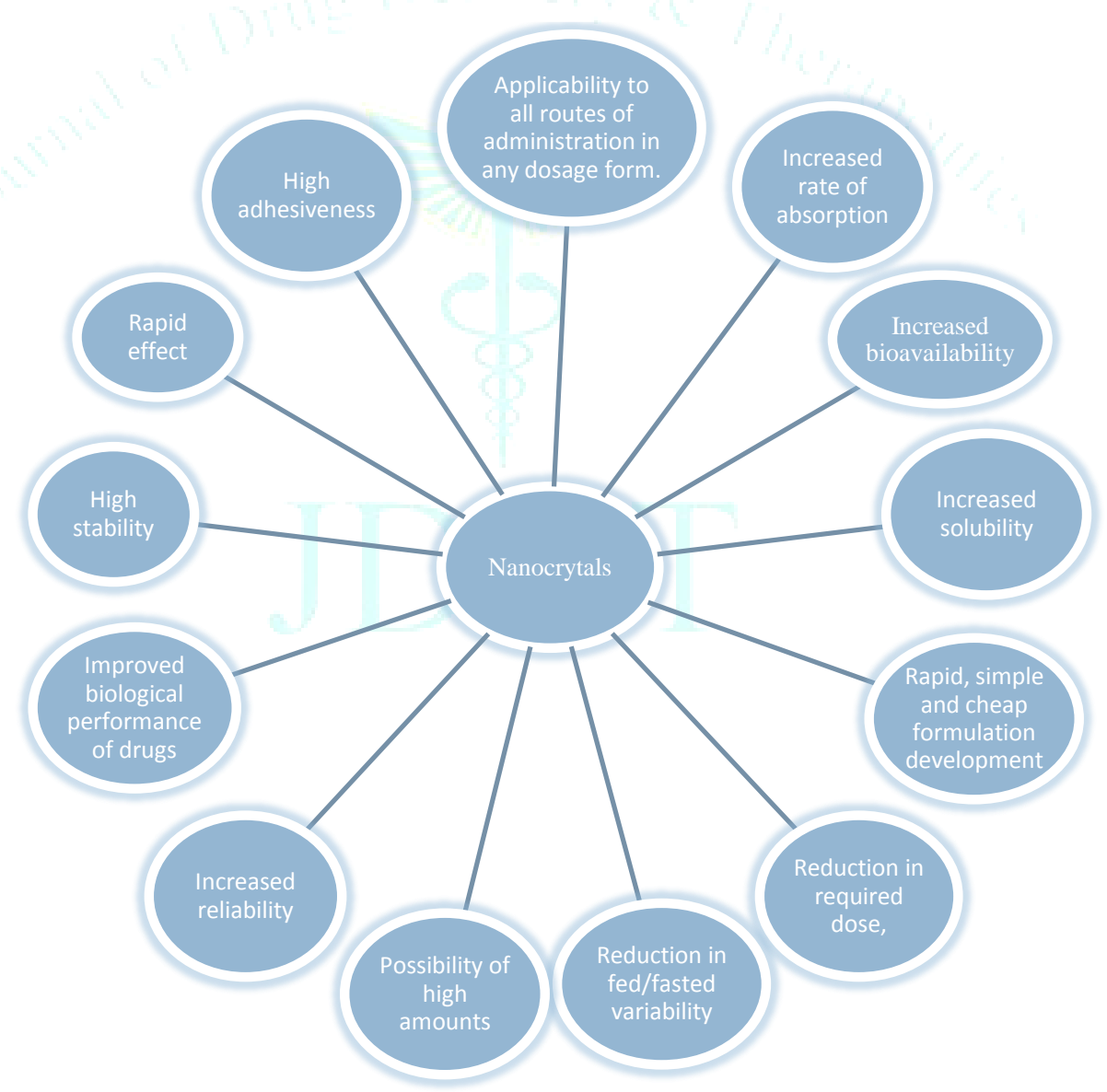

Figure 2: Advantages of nanocrystals

\section{Limitations}

a Limited to only BCS II class drug only.

a High cost instruments are required for production of drug nanocrystal that increase the cost of dosage form.

a The formation of nanocrystals and their stability is depend on the molecular structure of the drug, so only certain classes of compound will qualify. ${ }^{9}$ 


\section{Properties:}

Increase of dissolution velocity by surface area enlargement:

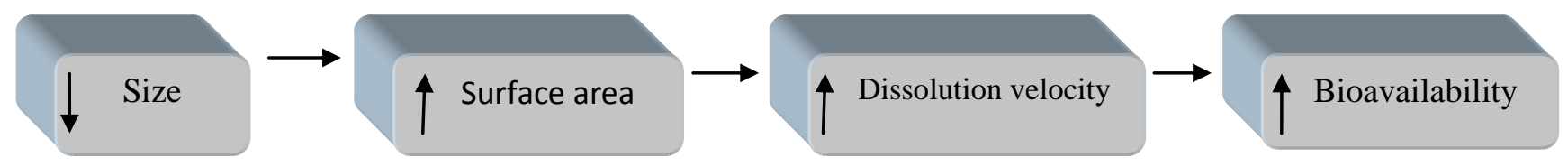

The dissolution rate is proportional to the surface area available for dissolution as described by the Noyes-Whitney equation:

$$
d c / d t=\frac{D \cdot A(\mathrm{Cs}-\mathrm{Cx})}{h}
$$

Where:

$$
\begin{aligned}
& \mathrm{dc} / \mathrm{dt}=\text { dissolution velocity } \\
& \mathrm{D}=\text { diffusion coefficient } \\
& \mathrm{A}=\text { surface area } \\
& \mathrm{c}_{\mathrm{s}}=\text { saturation solubility } \\
& \mathrm{c}_{\mathrm{x}}=\text { bulk concentration } \\
& \mathrm{h}=\text { diffusional distance over which the concentration gradient occurs. }^{10,11}
\end{aligned}
$$

\section{$>$ Increase in saturation solubility :}

The saturation solubility $\mathrm{c}_{\mathrm{s}}$ is a constant depending on the compound, the dissolution medium and the temperature. However, below a critical size of $1-2 \mu \mathrm{m}$, the saturation solubility is also a function of the particle size. It increases with decreasing particle size below $1000 \mathrm{~nm}$. Therefore, drug nanocrystals possess increased saturation solubility.

The Ostwalde Freundlich equation directly describes the relation between the saturation solubility of the drug and the particle size

$$
\log \frac{C_{\mathrm{S}}}{C_{\alpha}}=\frac{2 \sigma V}{2.303 R T \rho r}
$$

Where: particles,

$$
\begin{aligned}
& \mathrm{Cs}=\text { saturation solubility, } \\
& \mathrm{C} \square=\text { solubility of the solid consisting of large }
\end{aligned}
$$

$\mathrm{r}=$ interfacial tension of substance,

$\mathrm{V}=$ molar volume of the particle material,

$\mathrm{R}=$ gas constant,

$\mathrm{T}=$ absolute temperature

$\mathrm{r}=$ radius of particle

\section{$>$ An increased adhesiveness to surface/cell membranes:}

Increased adhesiveness is also due to the increased surface area available for interaction. The increased adhesiveness of nanomaterials is usually due to an increased contact area of small particles versus large particles (at identical total particle mass). Similar to other nanoparticles, drug nanocrystals show an increased adhesiveness to tissue which lead to an improvement of oral absorption of poorly soluble drugs apart from the increased saturation solubility and dissolution rate

\section{Properties of nanocrystals}

1 - Size below $1 \mu \mathrm{m}$

$2-100 \%$ drug, no carrier

3 - Generally needed to be stabilized

4 - Crystalline or amorphous structure

5 - Increase of dissolution velocity

6 - Increase in saturation solubility

7 - Amorphous particle state offers advantages

\section{Stabilization of drug nanocrystals}

Drug nanocrystals are nanosized solid drug particles surrounded by a stabilizer layer. Often nanocrystals are considerably easy to produce, but the stability and the selection of stabilizer is the most challenging and critical step. Stabilizers stabilize the newly formed drug nanocrystals, but they also have an important role in further formulation and they even affect the drugs bioavailability. Mostly, the stabilizer selection is based purely on the requirement of physical stability, e.g., maintaining the nanosized particle size as long as possible after the formation of drug nanocrystals. ${ }^{12}$

The massive surface area of nanocrystals results in sufficiently high free energy or surface charge that might cause attraction or agglomeration. Small sized nanocrystals sometimes raise the solubility of drug beyond the saturation point which promotes recrystallization into larger particles; also known as 
Ostwald ripening. These processes ultimately lead to irreversible loss of formulation integrity. ${ }^{12,13}$

Agglomeration is prevented by the presence of stabilizers in the nano-formulation. Stabilizers can spontaneously adsorb on and cover the newly formed particle surface to (a) decrease the free energy of system and interfacial (surface) tension of particles; (b) form a dense hydrophilic layer around hydrophobic particles, provide steric hindrance and steep repulsions between the particles (steric stabilization); (c) charge the particle surface if the stabilizer has ionizable groups, which increase the repulsive force (electrostatic stabilization); (d) combine the steric and electrostatic stabilization. ${ }^{14}$

\section{Aggregation and Collision mechanism}

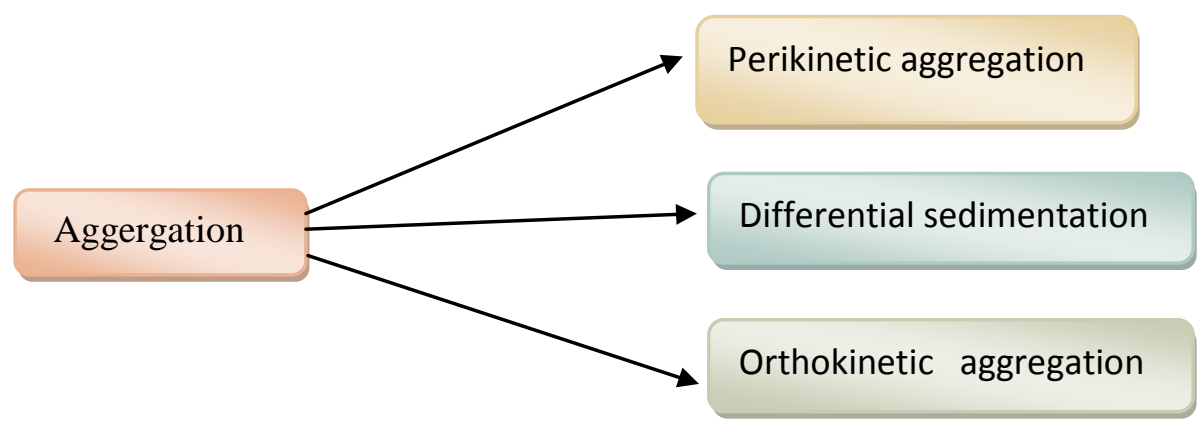

- Perikinetic aggregation: - If the collisions are caused by Brownian motion,the process is called perikinetic aggregation and is solely driven by diffusion. Small particles in colloidal suspensions continuously undergo Brownian motion. These particles collide with each other and stick together due to attractive forces acting between them.

- Differential sedimentation: - Particles of different diameters settle at different velocities causing the

faster moving particles to collide with the slower moving particles resulting in aggregation.

- Orthokinetic aggregation: - Such collisions occur under conditions of shear, either by stirring or by flow. Orthokinetic aggregation is dependent on the initial particle size and velocity gradient, but is independent of temperature. ${ }^{13,14}$

\section{Classification of the stabilizers}

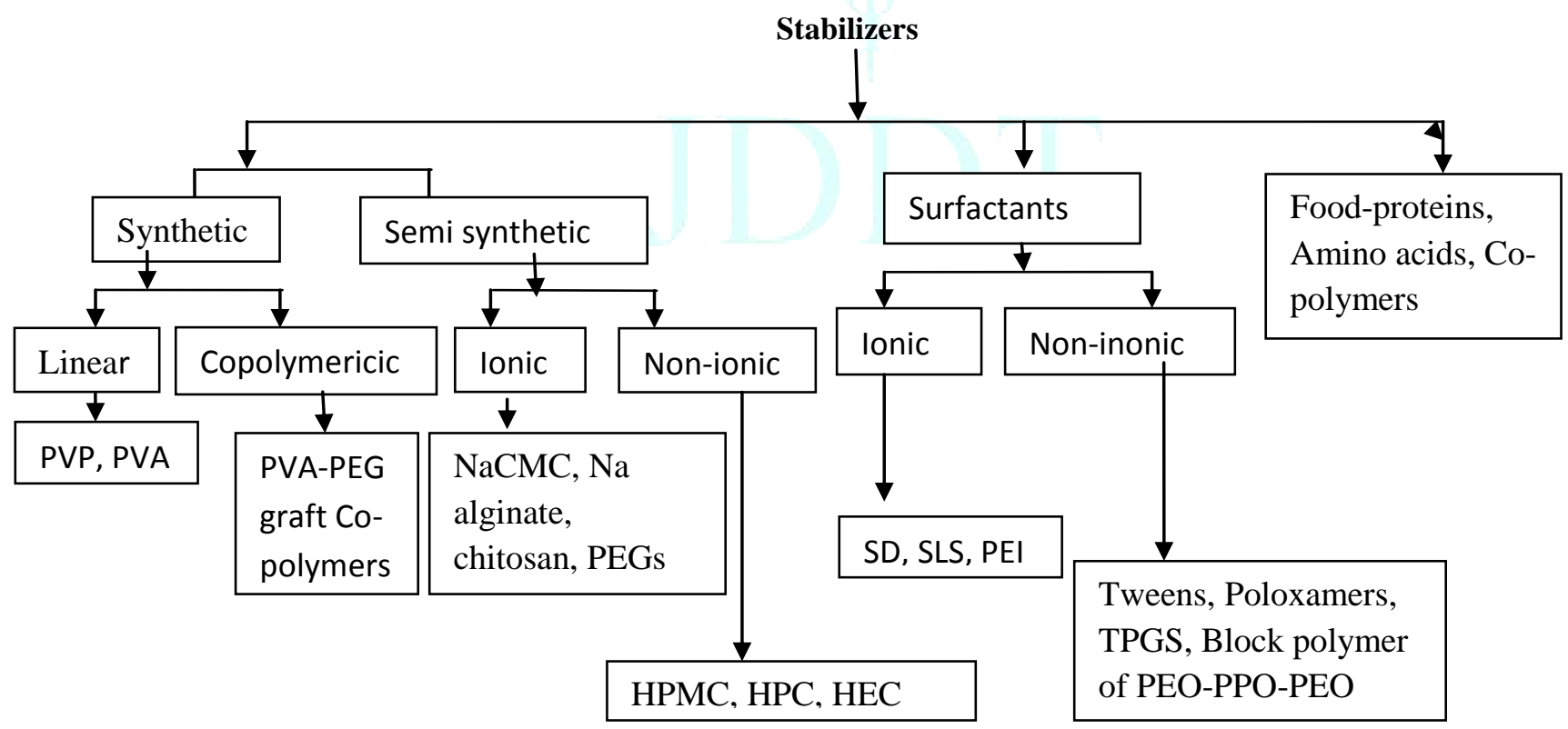

$\mathrm{PVP}=$ Povidone

PEG = Polyethylene glycol

HPC $=$ Hydroxypropyl cellulose
PVA = Polyvinyl alcohol, $\quad$ TPGS $=$ D- $\alpha$-tocopheryl polyethylene glycol succinate HPMC $=$ Hypromellose Cellulose PEO = Polyethylene oxide

HEC = Hydroxyethyl Cellulose PPO = Polypropylene oxide

$\mathrm{SD}=$ Docusate sodium

PEI = Polyethylene imine 


\section{Mechanism of the stabilization}

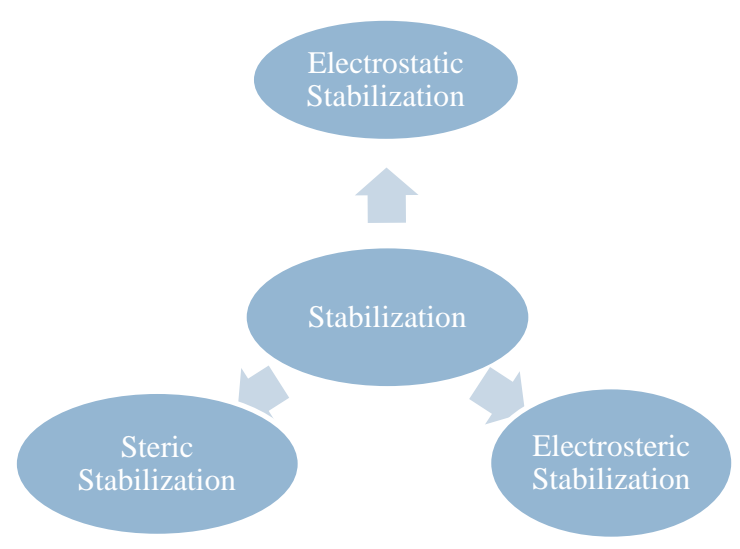

Figure 4: Mechanism

Electrostatic Stabilization: - Adsorption of the ions to the surface results in mutual repulsive forces between the particles. Increase in the ionic strength influence the repulsive force and reduce the thickness of electrical double layer which leads to a decrease in the repulsion potential of the particles.

Steric Stabilization: Adsorption of the non-ionic amphipathic particles on the surface of the particles. In the case of the steric stabilization, the adsorbed polymer does not possess electrostatic charge.

Electrosteric Stabilization: - Electrsteric stabilization is the combination of both above mentioned stabilizations. Electrosteric stabilization can also be provided by using a combination of two different stabilizers, an ionic surfactant and a polymer, respectively. ${ }^{12,14}$

Table 1: Mechanism of Stabilization

\begin{tabular}{|l|l|l|}
\hline Mechanism of stabilization & Stabilizing agent & Techniques \\
\hline Electrostatic & SLS, & Nanoprecipitation and Bead miling \\
\hline Steric & $\begin{array}{l}\text { HPMC,PVA K15, Poloxamer 188, } \\
\text { Poloxamer 407 }\end{array}$ & $\begin{array}{l}\text { Antisolvent precipitation, Ball milling,High } \\
\text { pressure homogenization, }\end{array}$ \\
\hline Electrosteric & $\begin{array}{l}\text { PVP K30, SLS, Poloxamer 188, } \\
\text { Lecithin }\end{array}$ & $\begin{array}{l}\text { High pressure homogenization, Emulsion } \\
\text { diffusion, }\end{array}$ \\
\hline
\end{tabular}

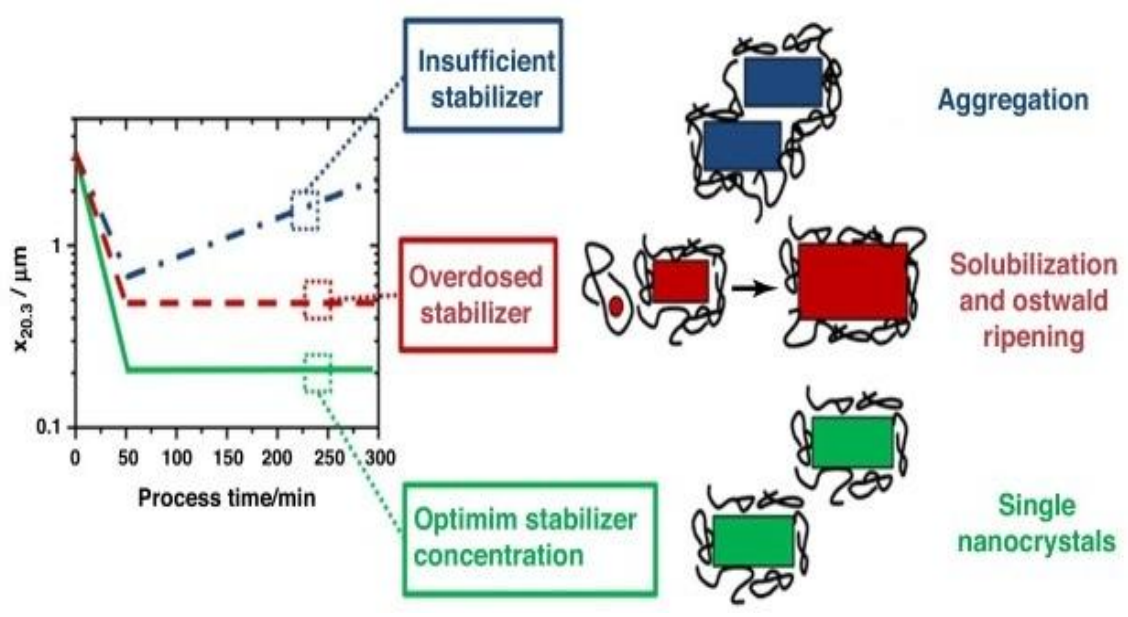

Figure 5: A suitable concentration of stabilizer should be present in the system to produce nanosuspensions with small particle size and to assure colloidal stability. Excess stabilizer should be avoided to prevent solubilization and increase of particle size due to Ostwald ripening 


\section{Selection of the stabilizer:}

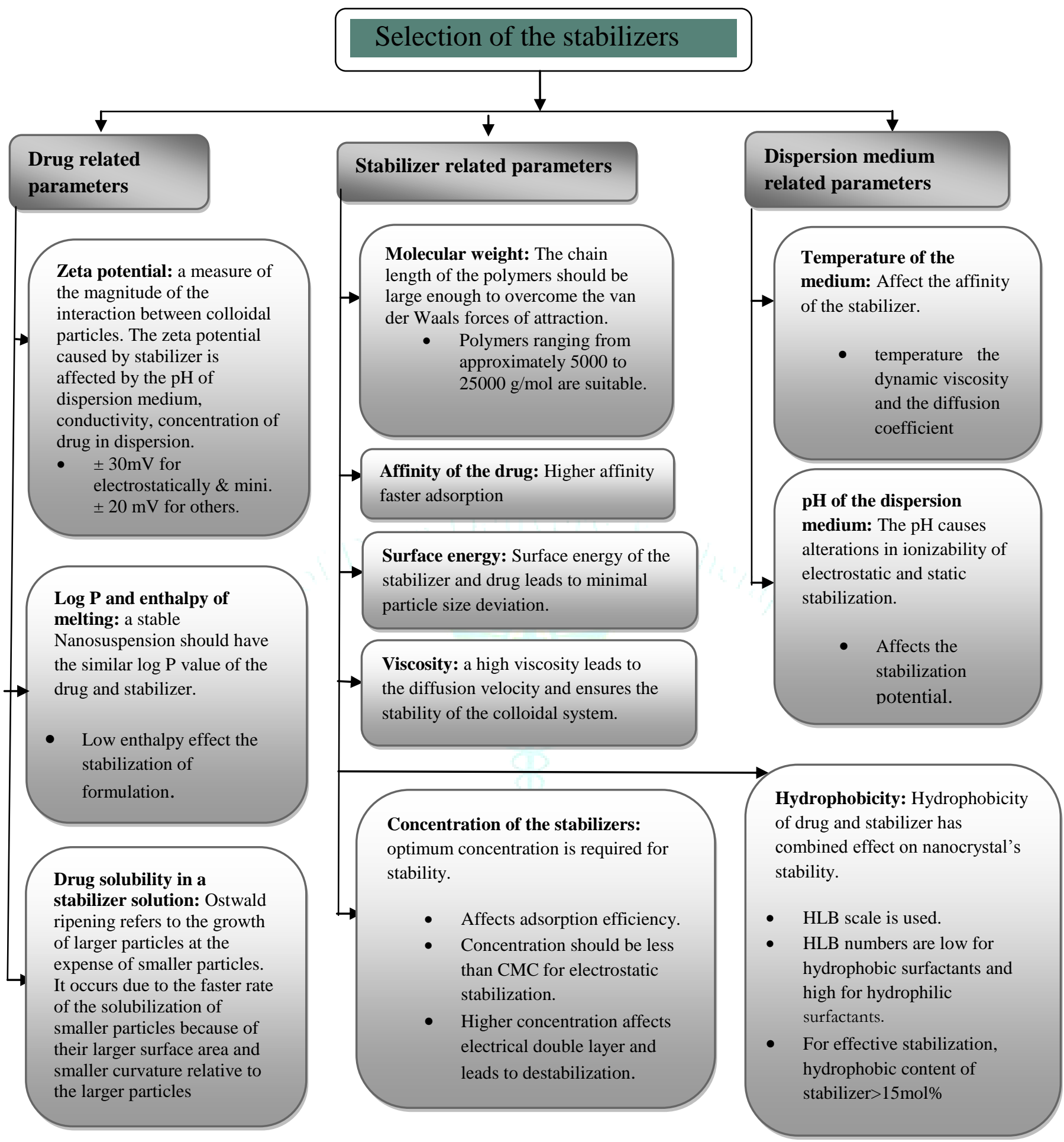




\section{Preparation of nanocrystals}

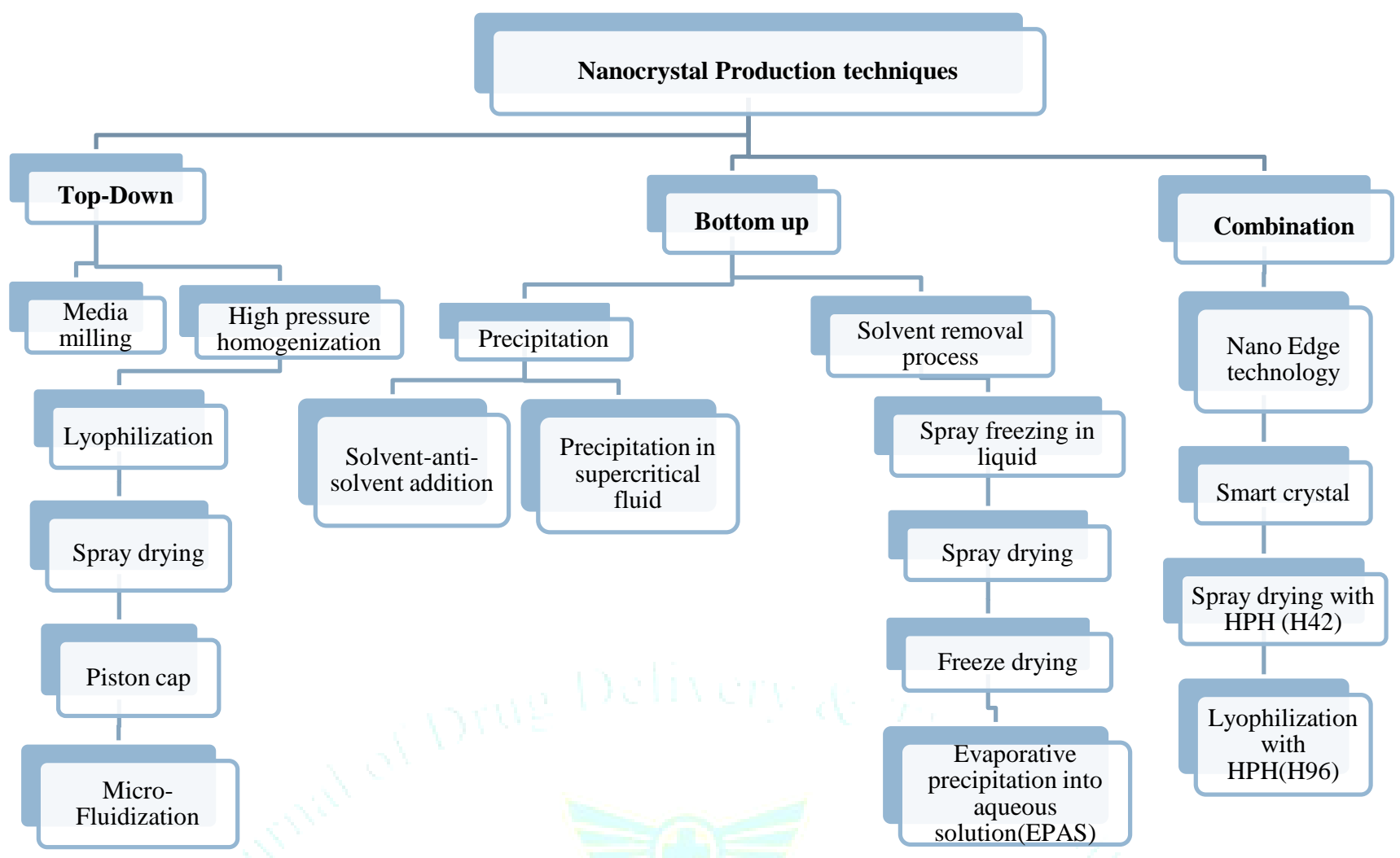

Two basic approaches are involved in production of nanocrystals, the bottom-up technologies (controlled precipitation/ crystallization) and the top-down technologies, nanonizing (large-size drug powder to be reduced in size, e.g. by mechanical attrition). However, the combination techniques, combining a pre-treatment with a subsequent size reduction step are also being employed. ${ }^{15,16}$

* Top - down method: In this technique large crystalline particles are reduced into small particles by shear forces.

\section{Media milling:}

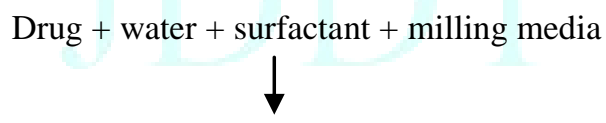

Add into the milling chamber

Generation of the shear force which reduce the particle size

Milling media contains Zirconium oxide, glass and polystyrene beads etc. The mill consists of the milling chamber, milling motor, milling pearls and recirculation chamber.

Process parameters: Amount of milling media and drug, rotation speed and time.

\section{Merits:}

$\checkmark \quad$ Low batch to batch variations

$\checkmark$ have low particle size distribution

$\checkmark \quad$ High efficiency of drug loading

\section{Demerits:}

$\checkmark$ Impurities in milling media is major concern

$\checkmark$ Intensive-energy use with long milling times ${ }^{16,17,18}$

High pressure homogenization (HPH): High energy disintegration process which use high energy to reduce size. In this method, drug suspension is passed through a narrow gap of $25 \mu \mathrm{m}$ results in formation of cavitation, collision among the particles and high shear force leading to size reduction. Two homogenizer types normally applied are the piston-gap homogenizer and microfluidizer homogenizer. 


\section{Merits:}

$\checkmark$ used for the production of dilute as well as concentrated nanosuspension with low particle size distribution

$\checkmark \quad$ Less batch to batch variation

$\checkmark \quad$ Water free production possible

\section{Demerits:}

$\checkmark$ High energy technique

$\checkmark$ Suspension formation need

$\checkmark \quad$ Micronized drug particles needed

$\partial \quad$ Piston gap homogenizer: The drug is dispersed in an aqueous surfactant solution which is then forced by a piston through tiny homogenisation gap under high pressure.

$\partial \quad$ Micro fluidizer technology: The principle is based on jet steaming. Two stream of liquid with high velocity collide frontally under high pressure. The particle size is reduced due to high shear force particle collision and cavitation. The collision chamber can be either Y-type or Z-type in shape. Surfactants or phospholipids are required to stabilize the desired particle size. ${ }^{18,19}$

* Bottom up method: Oldest technique to prepare drug nanocrystals.Also known as Precipitation method. In this method, drug is dissolved in a solvent system which is miscible with the anti solvent. Mostly, water is used as anti-solvent.The preparation process involves two steps

Step 1: Preparation of drug solution in organic solvents: Concentration of drug solution was prepared by preparing solution of drug in organic solvent (based on solubility of drug in particular solvent).

Step 2: Addition of drug solution in water: The above prepared drug solution was added into required quantity of water containing polymeric stabilizers (PVP K30, Poloxamer 188, Poloxamer 407, combination of PVP K30 and Poloxamer 407 and combination of PVP K30 and Poloxamer 188) with continuous stirring. Immediately, particles precipitated from the antisolvent and a milk-like suspension formed which was then filtered and dried. Drying was carried out using tray dryer at $40^{\circ} \mathrm{C}$

With the improvement in bottom-up technology, several other technology were developed based on precipitation method such as RESS and SAS techniques supercritical fluids are used as solvent or anti-solvent depend on the drug's solubility. EPAS technique was developed for which are soluble in water immiscible solvents. Examples of products manufactured by the precipitation method are: Hydrosols and NanomorphTM, which are developed by Sucker and Soliqs/Abbott respectively

Process parameter: Nature of solvent and antisolvent, Rate of addition of solvent to antisolvent, Ratio of solvent to antisolvent, Drug concentration in solvent, Type and amount of stabilizeretc

Merits:

$\checkmark \quad$ Ultrafine particles $(<100 \mathrm{~nm})$ can be obtained $\checkmark$ Low cost

$\checkmark \quad$ finely dispersed drug

$\checkmark$ Involve the controlled precipitation/crystallization of drug from its solution state

\section{Demerits:}

$\checkmark \quad$ Subsequent particle growth which affect the solid state stability of nanocrystals

$\checkmark$ Poor redispersibility

$\checkmark$ Residual solvent content ${ }^{19,20,21,22}$

$>\quad$ Supercritical Fluid Crystallization: Supercritical fluid (SCF) existing at temperatures above their critical temperature and pressures beyond their critical pressure has low density, viscosity and high diffusivity. Most processes involve carbon dioxide as the SCF because it is nontoxic, nonflammable and inexpensive. This method could be classified by the principle of either the SCF fluid is used as solvent or anti-solvent. In this process, the supercritical fluid can be rapidly removed without lengthy drying. ${ }^{23,24}$

$>$ Rapid Expansion of Supercritical Solutions (RESS): This process is also known as supercritical fluid nucleation (SFN), which can be used for API that exhibits an efficient solubility in supercritical carbon dioxide $\left(\mathrm{SCO}_{2}\right)$. The API is firstly dissolved in $\mathrm{SCO}_{2}$ in a high pressure vessel. The solution is then depressurized through a nozzle into the ambient environment, which results in the formation of the nanocrystals. $^{25,26}$

Spray Drying: Spray drying is the most widely used and studied solvent evaporation method. In spray drying, the colloidal particles or sols are typically used as precursors. Then the fine droplets are evaporated in a warm air current to form dry particles. This method has been commonly used for the production of microparticles and solid lipid nanoparticles (SLNs) but still has limits to formulate nanocrystals. ${ }^{25,26}$

* Combination technology: Combination technology is developing to overcome the problems of the top down and bottom up methods. This method is the combination of top down and bottom up methods. This technology is the two step process.

First step pre- treatment process (bottom up) and second step is reduction of the particle size. In second step, high pressure homogenization is used. This process is known as annealing. Annealing is the process of converting the unstable matter into the stable form by single or repeated application of energy, followed by thermal relaxation. The nanocrystals generated using combination technology has particle size below $200 \mathrm{~nm}$.

Nowadays, five combinative methods are known

\section{- NANOEDGE}

- $\mathrm{H} 42$

- H69

- H96 


\section{NANO EDGE technology}

The drug is first dissolved in a suitable solvent, usually a water-miscible organic solvent

The drug solution is then mixed with a second aqueous liquid in which the drug is less soluble

The aqueous liquid can contain surfactants for stabilization, and it is added to the drug solution in a controlled manner

The precipitation occurs due to the change in solubility

The microprecipitation is a pretreatment and drug particles can be obtained in amorphous or semicrystalline form.

The drug particles are reduced in size by employing HPH.

The residues of organic solvents in the nanosuspension are a major problem associated with this combinative technology, which becomes more complicated in the case of large-scale production (i.e., larger amounts of solvent to be removed from the final drug product).

\section{H42 technology:}

In this technology, spray drying (SD) is the first unit operation, the poorly soluble compound is dissolved in organic solvents. Surfactants such as poloxamer or sugars such as mannitol can be added to the drug solution to improve the results of the drying step. The obtained spray-dried drug powders are then dispersed in aqueous media containing surfactants for stabilization purposes. The suspensions are further processed to nanosuspensions by employing the HPH technique.

\section{H69 Technology:}

It combines amicroprecipitation step involving organic solvents, followed by high pressure homogenization for particle size reduction. To employ this combinative technique, the drug is dissolved in a suitable solvent, which is then mixed with an aqueous nonsolvent. The nonsolvent is added to the solvent in a controlled manner.The liquid flows come in contact, which results in the precipitation of the drug. The particle formation takes place in the high-energy zone of a homogenizer, where the just-formed drug particles are immediately treated with cavitation, particle collision, and shear forces. $^{22,23,24,25}$

\section{Nanocrystal based formulations}

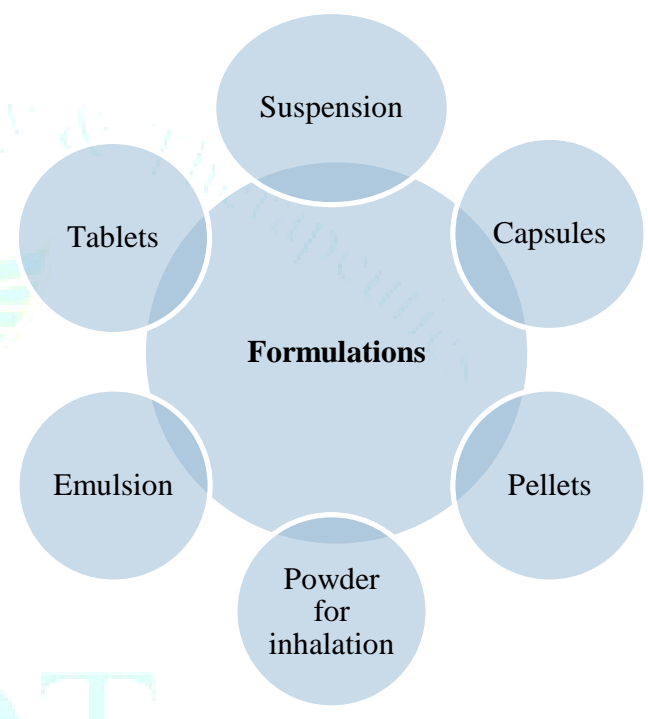

Figure 6: Formulations of nanocrystals

\section{Route of administration for nanocrystals}

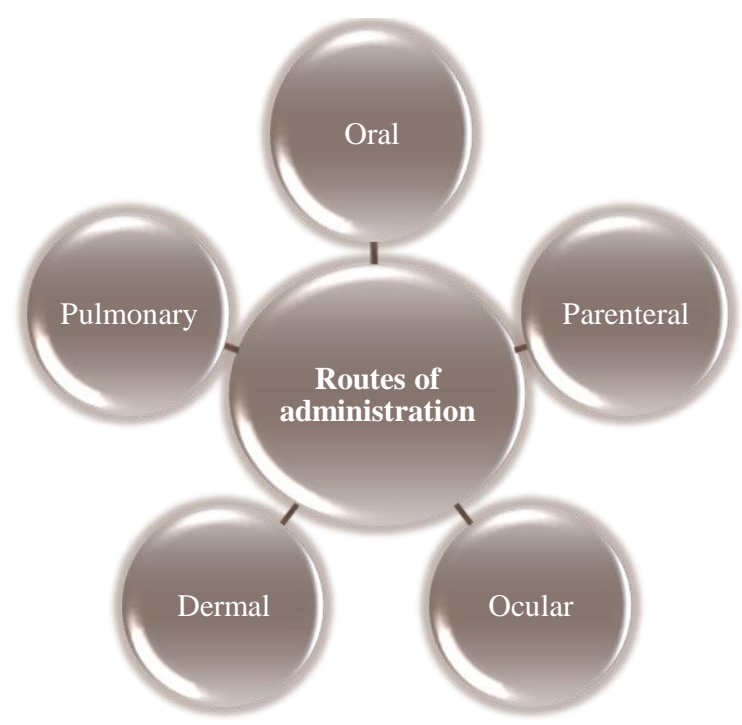

Figure 7: Route of administration

Applications of nanocrystals in drug delivery 
* Oral delivery: Oral administration is the most popular approach for drug delivery system due to its safety and convenience, especially for poorly soluble drugs. The performance of oral drugs is determined by their solubility in digestive juice and circulation in gastrointestinal tract. ${ }^{27}$ An oral controlled release formulation in combination with nanocrystal technology proved to be extremely beneficial especially for poorly soluble drugs. The combined technology enhances the flexibility of dosage form, quenching the need of alternative drug forms (like salt, prodrug etc), high drug loading and optimizing drug delivery. Besides, improved dose proportionality and reduction of fed/fast effect was also observed. Elan Drug Technologies have commercially introduced various products using this combined technology. ${ }^{28,29}$

* Ocular drug delivery: Ocular drug delivery looking at the potential benefits of nanocrystals in oral drug delivery, their application is also explored for ocular drug delivery by several researchers includes detailed application of nanocrystal in ocular drug delivery. Not a single nanocrystal-based product is available in market for treatment of ocular diseases. This may be due to existence of patent on the use of production techniques for the development of nanocrystals. Research has proved the advantages of nanocrystals in ocular drug delivery which establish hope for the treatment of various ocular diseases as well as development of better alternative formulation for poorly soluble.

- Improved ocular safety

- Enhanced corneal permeation

- Enhanced ocular bioavailability

- Dual drug release behavior in the eye

- Improved tolerability ${ }^{28,29,30}$

* Dermal drug delivery: Dermal delivery of nanocrystals was a route of administration that was not fully exploited until relatively recently, despite the advantages of nanocrystals, such as adhesion, fast dissolution, and increased penetration, that can be useful for dermal application. The development of nanocrystals for delivery to the skin was first exploited in the field of cosmetics and it was later expanded for drug delivery purposes. Specifically, the cosmetic products Juvedical 1 (Juvena of Switzerland, Juvena Marlies Mo“ller AG) and Platinum Rare collection (La Prairie 1) contain nanocrystals of the antioxidants rutin and hesperidin, respectively. ${ }^{29,30,31}$

- Parenteral drug delivery: Implementation of nanocrystal technology enhances the performance of the parenterally injected poorly soluble drugs. It replaces organic solvents by aqueous-based solvents, reduces dose volume by improving drug loading, faster dissolution (due to nano size) and avoiding macrophage uptake. From a safety point of view, nanocrystals permit sterile filtering; also avoid use of any harsh excipients. ${ }^{31,32}$

Pulmonary drug delivery: For an optimal pulmonary drug delivery, particles with appropriate aerodynamic size, shape and density are the stringent requirements as the maximum particle size for central airways deposition is approximately 5 $\mu \mathrm{m}$. Generally, jet milled suspension aerosols or dry powders (usually micron sized) have been used for pulmonary delivery but often show below par performance that includes poor flow ability, low bioavailability (due to limited diffusion attributed to micro particulate nature of drugs), and unwanted deposition in mouth \& pharynx. Nanocrystal technology offers preferential deep lung delivery of drugs either for systemicor local effect and exploiting nanosuspension is an ultimate and attractive approach in this regard. ${ }^{32}$ Moreover, it is suitable for use with ultrasonic and compressed air nebulizers with faster nebulization times. It is applicable to a wide range of drug molecules for inhalation either in the form of liquid droplets or powder. ${ }^{33,34,35}$

Characterization parameters

\begin{tabular}{|l|l|l|}
\hline S.No. & Characterization parameters & Methods \\
\hline 1. & Mean particle size and size distribution & $\begin{array}{l}\text { Transmission Electron Microscopy(TEM), Scanning } \\
\text { Electron Microscopy (SEM), Environmental Scanning } \\
\text { Electron Microscopy (ESEM }\end{array}$ \\
\hline 2. & Structure and morphology & $\begin{array}{l}\text { Light microscopy, Scanning electron microscopy, } \\
\text { transmission, Electron microscopy, Field emission } \\
\text { scanning electron microscopy, Atomic force microscopy }\end{array}$ \\
\hline 3. & Surface charge & Zeta potential \\
\hline 4. & $\begin{array}{l}\text { Rheological properties(for liquid nano } \\
\text { suspensions) }\end{array}$ & Viscometer, rheometer \\
\hline 5. & Solid state analysis(crystalline & $\begin{array}{l}\text { Powder X-ray diffraction, Differential } \\
\text { calorimetry }\end{array}$ \\
\hline 6. & Solubility & sVanning \\
\hline 7. & Concentration determination & Fluorescence spectroscopy \\
\hline
\end{tabular}


Nanocrystalline-based products approved by the FDA

\begin{tabular}{|c|c|c|c|c|c|c|c|}
\hline $\begin{array}{l}\text { Trade } \\
\text { name }\end{array}$ & Company & Active substance & Indication & $\begin{array}{l}\text { Particle size } \\
\text { reduction } \\
\text { method }\end{array}$ & Route & $\begin{array}{l}\text { Dosage } \\
\text { form }\end{array}$ & Year \\
\hline Avinza $^{(B)}$ & King Pharma & Morphine sulfate & Pain medication & WMM & Oral & Capsule & 2002 \\
\hline Azopt ${ }^{\circledR}$ & Alcon & Brinzolamide & $\begin{array}{l}\text { Ocular } \\
\text { hypertension }\end{array}$ & WMM & Ocular & Suspension & 1998 \\
\hline Cesamet@ & Lilly & Nabilone & Antiemetic & Precipitation & Oral & Capsule & 2005 \\
\hline Emend® & Merck & Aprepitant & Antiemetic & WMM & Oral & Capsule & 2003 \\
\hline $\begin{array}{l}\text { Focalin } \\
\text { XR® }\end{array}$ & Novartis & $\begin{array}{l}\text { Dexmethylphenida } \\
\text { te } \mathrm{HCl}\end{array}$ & ADHD & WMM & Oral & Capsule & 2001 \\
\hline Gris-Peg® & Novartis & Griseofulvin & Antifungal & Precipitation & Oral & Tablet & 1982 \\
\hline $\begin{array}{l}\text { Herbesser } \\
\text { (®) }\end{array}$ & Mitsubishi & Diltiazem & Hypertension & WMM & Oral & Tablet & 2002 \\
\hline $\begin{array}{l}\text { Invega } \\
\text { Sustenna }\end{array}$ & $\begin{array}{l}\text { Johnson \& } \\
\text { Johnson }\end{array}$ & $\begin{array}{l}\text { Paliperidone } \\
\text { palmitate }\end{array}$ & Antipsychotic & WMM & $\begin{array}{l}\text { Intramu } \\
\text { scular }\end{array}$ & $\begin{array}{l}\text { Suspension } \\
\text { in prefilled } \\
\text { syringe }\end{array}$ & 2009 \\
\hline $\begin{array}{l}\text { Megace } \\
\text { ES® }\end{array}$ & $\begin{array}{l}\text { Par } \\
\text { Pharmaceutic } \\
\text { al }\end{array}$ & Megestrol acetate & Appetite stimulant & WMM & Oral & Suspension & 2005 \\
\hline Naprelan ${ }^{\circledR}$ & Wyeth & Naproxen sodium & NSAID & WMM & Oral & Tablet & 2006 \\
\hline $\begin{array}{l}\text { Rapamune } \\
\text { ( }\end{array}$ & Wyeth & $\begin{array}{l}\text { Sirolimus } \\
\text { (rapamycin) }\end{array}$ & $\begin{array}{l}\text { Immunosuppressa } \\
\mathrm{nt}\end{array}$ & WMM & Oral & $\begin{array}{l}\text { Suspension, } \\
\text { tablet }\end{array}$ & 2000 \\
\hline $\begin{array}{l}\text { Ritalin } \\
\text { LA® }\end{array}$ & Novartis & $\begin{array}{l}\text { Methylphenidate } \\
\mathrm{HCl}\end{array}$ & ADHD & WMM & Oral & Capsule & 2002 \\
\hline Theodur® & $\begin{array}{l}\text { Mitsubishi } \\
\text { Tanabe } \\
\text { Pharma }\end{array}$ & Theophylline & Asthma, COPD & WMM & Oral & $\begin{array}{l}\text { Tablet, } \\
\text { Capsule }\end{array}$ & 2008 \\
\hline Tricor $\AA$ & Abbott & Fenofibrate & $\begin{array}{l}\text { Hypercholesterole } \\
\text { mia }\end{array}$ & WMM & Oral & Tablet & 2004 \\
\hline Triglide ${ }^{\circledR}$ & SkyePharma & Fenofibrate & $\begin{array}{l}\text { Hypercholesterole } \\
\text { mia }\end{array}$ & HPH & Oral & Tablet & 2005 \\
\hline Verelan $@$ & $\begin{array}{l}\text { Schwarz } \\
\text { Pharma }\end{array}$ & Verapamil $\mathrm{HCl}$ & Hypertension & WMM & Oral & Capsule & 1998 \\
\hline Zanaflex® & Acorda & Tizanidine $\mathrm{HCl}$ & Muscle relaxant & WMM & Oral & Capsule & 2002 \\
\hline
\end{tabular}

\section{CONCLUSION}

Nanocrystal technology is evidently suitable for drugs with poor solubility. Drug nanocrystals can be applied to all poorly soluble drugs to overcome their solubility and bioavailability problems. The decrease in particle size to nanometer range contributes to the increased particle surface, curvature, saturation solubility, dissolution velocity and further acceptable bioavailability. Various applied and combination technologies are developed for the production of drug nanocrystals. At present, drug nanocrystals are paid increasing more attention as a promising approach owing to many reasons such as an increasing number of poorly soluble drugs in drug development process, pharmacoeconomic value, easier production, safer composition and other advantages that are previously mentioned.

\section{FUTURE PROSPECTS}

Compared with traditional nanocarriers, the advantages of nano- crystals in physical stability, high drug loading and relative ease of production bring attractive alternatives for delivery of poorly soluble drugs. The use of drug nanocrystals is a universal formulation approach to increase the therapeutic performance of these drugs in any route of administration. Almost any drug can be reduced in size to the nanometer range. Most of the research has focused on the discovery of novel technologies for producing nano-crystals. These technologies have been patented both by drug delivery and pharmaceutical companies. As a result, wide selections of technologies are now available in the market. The research on nano-crystals is currently focused on the mechanistic understanding of drug/stabilizer interactions to provide a scientific framework for the selection of stabilizers. 


\section{REFERENCES}

1. Peltonen L, Hirvonen J, Drug nanocrystals - Versatile option for formulation of poorly soluble materials, International Journal of Pharmaceutics, 2018; 537:73-83.

2. Sinha B, Müller Rainer H., Möschwitzer JP., Bottom-up approaches for preparing drug nanocrystals: formulations and factors affecting particle size, International Journal of Pharmaceutics, 2013;13:35-5.

3. Chen H, Khemtong C, Yang X, Chang X, Gao J, Nanonization strategies for poorly water-soluble drugs, Drug Discovery Today,2011; 662:1-7

4. Sawant SV, Kadam VJ, Jadhav KR., and Sankpal SV, Drug Nanocrystals: Novel Technique For Delivery Of Poorly Soluble Drugs, International Journal Of Science Innovations And Discoveries, 2011; 1(3):1-5.

5. Patel V, Sharma Om P and Mehta T, Nanocrystal: a novel approach to overcome skin barriers for improved topical drug delivery, Expert Opinion on Drug Delivery, 2018.

6. Ahuja Bhupesh K., Jena Sunil K., Paidi Sharan K., Bagri S. and Suresh S., Formulation, optimization and in vitro-in vivo evaluation of febuxostat nanosuspension, International Journal of Pharmaceutics, 2014; 478:540-552.

7. Sarasija S, Singh C, Jena SK, Bagri S and Ahuja BK, Nanocrystals: A Novel Approachfor Drug Delivery, Department of Pharmaceutical Technology (Formulations), NIPER, 2014.

8. Srivalli Kale MR, Mishra B, Drug nanocrystals: A way toward scale-up, Saudi Pharmaceutical Journal, 2014; 24:386-404.

9. Patel A. P., Patel J. k., Patel KS., Deshmukh AB., Mishra BR., A Review On Drug Nanocrystal A Carrier Free Drug Delivery, International Journal Of Ayurveda \& pharmacy, 2011; 2(2):448-458.

10. Müller Rainer H, Junghanns Jens-Uwe A H, Nanocrystal technology, drug delivery and clinical applications, International Journal of Nanomedicine 2008; 3(3):295-309.

11. Nagarwal RC, Kumar R, Dhanawat M, Das N and Pandit J.K., Nanocrystal Technology in the Delivery of Poorly Soluble Drugs: An Overview, Current Drug Delivery, 2011.

12. Tuomela A, Hirvonen J and Peltonen L, Stabilizing Agents for Drug Nanocrystals: Effect on Bioavailability, Multidisciplinary Digital Publishing Institute, 2016; 8(16):118.

13. Pawar VK., Singh Y, Meher J G, Gupta S, Chourasia MK., Engineered nanocrystal technology: In-vivo fate, targeting and applications in drug delivery, Journal of Controlled Release, 2014.

14. Shete G, Jain H, Punj D, Prajapat H, Akotiya P, Bansal AK, Stabilizers used in nano-crystal based drug delivery systems,International Pharmaceutical Excipients Council, 2014; 5(4):184-209.

15. Shegokar R, Müller Rainer H., Nanocrystals: Industrially feasible multifunctional formulation technology for poorly soluble actives, International Journal of Pharmaceutics, 2010; 399:129-139.

16. C.S Neethu, V.B Kavitha, B Dineshkumar, K Krishnakumar and John A, Nanocrystals Drug Delivery System - A Review, Current Research in Drug Targeting, 2014; 4(1):1-5.

17. Nekkanti V, Vabalaboina V and Pillai R, Drug Nanoparticles - An Overview, www.intechopen.com.

18. Liu P, Nanocrystal formulation for poorly soluble drugs, Helsinki University Printing House, 2013
19. Bansal S, Bansal M and Kumria R, Nanocrystals: Current Strategies and Trends, International Journal of Research in Pharmaceutical and Biomedical Sciences, 2012; 3(1):406-419.

20. Peltonen L, Hirvonen J and Laaksonen T, Drug Nanocrystals and Nanosuspensions in Medicine, Division of Pharmaceutical Technology University of Helsinki, 2016.

21. Müller Rainer H., Gohla S and Keck Cornelia M., State of the art of nanocrystals - Special features, production, nanotoxicology aspects and intracellular delivery, European Journal of Pharmaceutics and Biopharmaceutics, 2011; 78:1-9.

22. $\mathrm{Lu} \mathrm{Yi,} \mathrm{Li} \mathrm{Ye} \mathrm{and} \mathrm{Wu} \mathrm{Wei,} \mathrm{Injected} \mathrm{nanocrystals} \mathrm{for} \mathrm{targeted}$ drug delivery, Acta Pharmaceutica Sinica B, 2016; 6(2):106113.

23. Katteboinaa S, Chandrasekhar V S R, Balaji. S, Drug Nanocrystals: A Novel Formulation Approach for Poorly Soluble Drugs, 2009; 1(3):682-694.

24. Balamarkonda $\mathrm{CH}$, Rao VS, Adamkhan $\mathrm{P}$, Nama S, Brahmaiah B, A Review On Significance Of Nanocrystals In Drug Delivery, International Journal Of Pharmacy , 2013; 3(2):56-61.

25. Salazar J, Müller Rainer H, Möschwitzer Jan P, Combinative Particle Size Reduction Technologies for the Production of Drug Nanocrystals, Journal of Pharmaceutics Volume 2014.

26. Gao Y, Wang J, Wang Y, Yin Q, Glennon B, Zhong J, Ouyang J, Huang X And Hao H, Crystallization Methods for Preparation of Nanocrystals for Drug Delivery System, Current Pharmaceutical Design, 2015; 21:3131-3139.

27. CHANG TL, ZHAN H, LIANG D, LIANG JF., Nanocrystal technology for drug formulation and delivery, Higher Education Press and Springer-Verlag Berlin Heidelberg 2015; 9(1):1-14.

28. Sharma OP, Patel V, Mehta T, Nanocrystal for ocular drug delivery: hope or hype, Drug Deliv. And Transl. Res.DOI 10.1007/s13346-016-0292-0

29. Malamatari M, Taylor Kevin M.G., Malamataris S, Douroumis D and Kachrimanis K, Pharmaceutical nanocrystals: production by wet milling and applications, Drug Discovery Today, 2018; 2149:1-14.

30. Gauniya A, Mazumder R, Pathak K, Nanocrystals: A Challenge for Improved Drug Delivery, Asian Journal of Biochemical and Pharmaceutical Research, 2014; 4(3):282292.

31. Raghvendra, Mishra A, A Review on Potential Applications of Nanocrystal Technology, Indian Journal of Pharmaceutical Science \& Research, 2013; 3(1):9-13.

32. Kawabata Y, Wada K, Nakatani M, Yamada S, Onoue S, Formulation design for poorly water-soluble drugs based on biopharmaceutics classification system: Basic approaches and practical applications, International Journal of Pharmaceutics, 2011; 42:1-10.

33. Möschwitzer JP., Drug nanocrystals in the commercial pharmaceutical development process, International Journal of Pharmaceutics, 2012

34. Zhao J, Liu Y, Wang L, Zhou Y, Du J and Wang Y, Functional and Modified Nanocrystals Technology for Target Drug Delivery, Journal of Nanoscience and Nanotechnology, 2018; 18(8):5207-5221.

35. Gao L, Zhang D And Chen M , Drug Nanocrystals For The Formulation Of Poorly Soluble Drugs And Its Application As A Potential Drug Delivery System, Technology And Applications, 2008; 10:845-862. 